\title{
Quantification of marine benthic communities with metabarcoding is highly influenced by ecological factors
}

\author{
Lise Klunder ${ }^{1}$, Judith van Bleijswijk ${ }^{2}$, Loran Kleine Schaars ${ }^{2}$, Henk van der Veer ${ }^{2}$, \\ Pieternella Luttikhuizen ${ }^{3}$, and Allert Bijleveld ${ }^{2}$ \\ ${ }^{1}$ Royal Netherlands Institute for Sea Research \\ ${ }^{2} \mathrm{NIOZ}$ \\ ${ }^{3}$ NIOZ Royal Netherlands Institute for Sea Research
}

April 28, 2020

\begin{abstract}
DNA metabarcoding methods have been implemented in studies aimed at assessing and quantifying marine benthic biodiversity. In such studies, first DNA is extracted from environmental samples, then target barcodes are amplified and subsequently sequenced. In order to use such methods in a quantitative manner, a relation between the biomass and/or the abundance of a species and the number of its DNA sequences is assumed. However, studies validating this relationship are rare. In this study, we validate measurements of biomass and abundance between traditional morphological and molecular approaches. A total of 126 samples from a benthic intertidal system were analysed and quantified using abundancy and biomass estimates from the morphological approach and frequency of occurrence and relative read abundance estimates from the molecular approach. A relationship between biomass and relative read abundance was only found for one taxon (Pygospio) but all other taxons failed to show such a relationship. We discuss how quantitative measurements by the molecular approach are hampered by the ecology of DNA, i.e., all the processes which determine the amount of DNA in the environment including the ecology of the benthic species.
\end{abstract}

\section{Introduction}

Marine benthic ecosystems are characterized by high biodiversity and are of global importance to climate, nutrient cycling and primary and secondary productivity (Snelgrove, 1997; Austen et al., 2002; Covich et al., 2004). From the intertidal to the deep sea, benthic fauna are central to the maintenance of these ecosystem services (Levin et al., 2001; Thrush et al., 2006). Effective monitoring of the benthic fauna is a first crucial step towards conservation of the marine benthic ecosystems (Patrício et al., 2009). Traditional benthic biodiversity assessments are based on the morphological identification of benthic species (see for instance Diaz et al., 2004; Compton et al., 2013). These morphological inventories are time-consuming, require scarce taxonomic expertise and are often limited to macrofauna species (Bucklin et al., 2011; Cardoso et al., 2011; Cowart et al., 2015). Thus, there is a need for methods which can assess marine benthic biodiversity in a rapid and cost-effective yet detailed and accurate manner (Aylagas et al., 2018).

In recent years, DNA metabarcoding methods have been successfully implemented in various studies to assess marine benthic biodiversity (Chariton et al., 2015; Guardiola et al., 2016; Lanzen et al., 2016; Sinniger et al., 2016 and many others). These methods provide the opportunity to assess the benthic community in a replicable manner which allows for the simultaneous recovery of a wide variety of taxa from all size classes without first isolating any organisms, facilitating rapid biodiversity monitoring (Yu et al., 2012). DNA metabarcoding most often relies on the extraction of DNA from a matrix of choice - sediment, water, air or a mixture of organisms - followed by the amplification of a DNA barcode via PCR (Hebert et al., 2003; 
Taberlet et al., 2012a). These DNA barcodes are sequenced, and the reads produced can be taxonomically assigned against globally available databases to infer information about the community.

Traditional benthic identification (morphological methods) often produce species abundance and/or biomass estimates to describe a community (Gray, 2000). Within these traditional methods, specimens are sorted and identified individually, and quantitative count or biomass estimates are acquired. The ability to acquire quantitative data, as opposed to qualitative data only, can greatly enhance the power of ecological studies (Gray, 2000; Yin and He, 2014). Quantitative measures were often used by early adopters of the metabarcoding method and these early adopters were hopeful this would relate to the quantitative measurements used in traditional benthic surveys (Chariton et al., 2010; Porazinski et al., 2010). Two main approaches can be distinguished in quantifying communities using a molecular method: a frequency of occurrence (FOO) approach and a relative read abundance (RRA) approach.

Within the frequency of occurrence approach, the presence of a taxon is counted over multiple samples and a higher occurrence is assumed to reflect a higher abundance of this taxon in the environment (Deagle et al., 2019). The FOO approach has been used extensively in dietary studies (i.g, De Barbra et al., 2014; Berry et al., 2017) and to a lesser extent in biodiversity studies (i.e., Chariton et al., 2015; Jeunen et al., 2019). The approach is a robust method. However, an overestimation of rare species might occur (Deagle et al., 2019). The second approach, transforming relative read abundance into biomass estimates, is the most widely adopted method in marine benthic studies (i.e., Sinniger et al., 2016; Cahill et al., 2018). Relative read abundance divides the number of reads for a taxon within a sample by the total number of reads for that sample and a higher number is assumed to indicate a higher abundance in the sample. Several studies report a positive relationship between relative read abundance and biomass for marine benthic species (Porazinski et al., 2010; Lejzerowicz et al., 2015). Also, a meta-analysis by Lamb et al. (2019) showed a weak but positive relationship for metabarcoding studies in comparison to traditional measurements using the RRA approach.

Whereas quantitative measurements in traditional morphological studies are direct measurements derived from the sample itself (e.g., specimens can be directly counted and weighed), the quantitative estimates derived from a molecular method are based on the critical assumption that the amount of DNA in a sample is a function of biomass. This indirect collection is subject to multiple methodological and ecological issues which can bias the quantitative estimates (Alberdi et al., 2018; Lamb et al., 2019). Additionally, the molecular methods encompass a line of steps (DNA extraction, amplification, sequencing, bioinformatic processing) before a dataset is ready for making inferences. Methodological issues have been discussed in much detail and for instance include: effectiveness of different DNA extraction approaches on different species (Brannock \& Halanych, 2015; Klunder et al., 2019); primer biases (Deagle 2014; Piñol et al., 2015; 2019) and biases induced in bioinformatic pipelines (Ficetola et al., 2015; Plummer \& Twin, 2015). Ecological issues have been discussed less, and include the release of DNA by its host; i.e., each species or individual has different shedding rates, based on morphological characteristics or seasonal patterns (Barnes \& Turner, 2016). But also, variable DNA quantity in different tissues (Pompanon et al., 2012) and the complexity of the environment (Elbrecht \& Leese, 2015). Nevertheless, many studies report their findings in a quantitative matter without validations, boldly hoping this relates to the quantitative measurements used in traditional methods (Deagle et al., 2019; Lamb et al., 2019).

The aim in this study is to explore to what extent traditional and metabarcoding approaches align in marine benthic communities. Specifically, whether metabarcoding outputs from DNA sediment samples can be used as a quantitative estimate for benthic macrofauna in the intertidal Dutch Wadden Sea. For this study, we chose to use a fast and easy sampling approach for the collection of eDNA samples, an approach which could readily be adopted in future monitoring programs. Simultaneously, we collected traditional morphology-based estimates of species occurrence and abundance. The first aim of the study was to examine whether detection rates for benthic macrofauna species in the field were comparable between molecular and traditional analyses. The second aim was to test the reliability of both a frequency of occurrence approach as well as a relative read abundance approach for these sampling methods.

\section{Methods}




\subsection{Sampling}

A total of 126 morphological and 126 molecular samples were collected at tidal flats north-east of the isle of Texel in the western part of the Dutch Wadden Sea (N53 $\left.06^{\prime} \mathrm{E} 4^{\circ} 54^{\prime}\right)$, divided over 7 sampling events between June 2016 and July 2017. Each sampling event comprised 18 stations within a 500m spatial range (Figure 1). At each station, two cores were taken simultaneously and directly adjacent to each other; one bigger core $\left(177 \mathrm{~cm}^{2}\right.$ surface, $25-30 \mathrm{~cm}$ depth) for the morphological identification of macrofauna and one smaller core $\left(5.60 \mathrm{~cm}^{2}, 10 \mathrm{~cm}\right.$ depth $)$ for the molecular identification.

\subsection{Morphological approach}

The morphological samples were washed over a 1-mm mesh sieve in the field and stored in the freezer. In the laboratory, samples were thawed and preserved in a $4 \%$ formaldehyde solution with Bengal rose. Species were sorted by hand and identified. Taxonomic identification was based on internal reference collection and WoRMS (2019). Individuals were counted and biomass (g) was determined as ash-free dry mass of the flesh. To decrease weighing error for small biomasses, specimens of small taxa such as Tharyx sp., Eteone sp., Oligochaeta sp. andPygospio sp. where only weighted for a minimum of four individuals and Heteromastus $s p$. was only weighted with a minimum of two individuals.

\subsection{Molecular approach}

The entire samples for molecular identification were rinsed twice with a saturated phosphate-buffer $\left(\mathrm{Na}_{2} \mathrm{HPO}_{4}\right.$; $0.12 \mathrm{M} ; \mathrm{pH}$ [?] 8) to remove extracellular DNA. The sediments were then cryodesiccated and ground in liquid nitrogen. Ten grams of the homogenized sediments served as starting material for the DNA extraction. DNA was extracted using the Powermax Soil DNA isolation kit (Qiagen Inc.) following the manufacturer's instructions. DNA from all extractions, as well as a mock sample (Table S1) were used as template for amplification in triplicate. A 450 base pair (bp) part of the nuclear small ribosomal subunit (18S) was amplified using the oligonucleotides F04 and R22 as primer pair (Sinnger et al., 2016). All forward and reverse primers were extended with $12 \mathrm{nt}$ unique barcodes based on the NEXTflex-HT barcodes. The $18 \mathrm{~S}$ gene was amplified in a $50 \mu \mathrm{l}$ volume reaction, containing $0.6 \mu \mathrm{M}$ of each primer, $0.2 \mu \mathrm{M}$ dNTP, $800 \mathrm{ng} / \mu \mathrm{L}$ BSA, $1 \mathrm{U}$ Phusion $\mathrm{R}$.

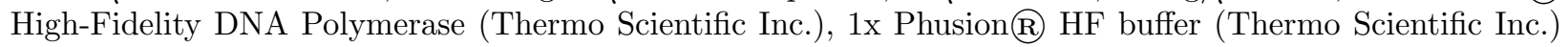
and $5 \mu \mathrm{L}$ of DNA extract. The thermal cycle conditions were as follows: an initial cycle of 30 seconds at $98^{\circ} \mathrm{C}$; followed by 27 cycles, each comprised of 10 seconds at $98^{\circ} \mathrm{C}, 20$ seconds at $60^{\circ} \mathrm{C}$ and 30 seconds at $72^{\circ} \mathrm{C}$, followed by a single cycle of five minutes at $72^{\circ} \mathrm{C}$. The PCR products were excised from a $1 \%$ agarose gel, purified using the Qiaquick Gel Extraction Kit (Qiagen, Inc.) and quantified with a Qubit 3.0 fluorometer (Qiagen Inc.). All samples were pooled in equimolar quantities together with blank PCR controls. The pooled sample was then subjected to a final purification using MinElute PCR Purification columns (Qiagen Inc.) as described by the manufacturer. The pooled sample was sequenced at Useq (Utrecht, Netherlands) on an Illumina MiSeq using the 2x 300bp V3 kit.

\subsection{Bioinformatics}

Raw sequences with a quality score [?] 30 over $75 \%$ of the nucleotide positions were discarded. Quality filtered reads were de-multiplexed allowing zero mismatches in both the forward and reverse barcode label. Subsequently, reads were dereplicated at a $100 \%$ similarity and uniques were discarded. The remaining sequences were clustered with a $98 \%$ similarity cut-off. Singletons were discarded and the remaining OTU-clusters were taxonomically assigned using the RDP Classifier (Wang et al., 2007) with a minimum confidence of 0.8 against the SILVA 18S rRNA database (release 132, Pruesse et al., 2007) and our local reference database (Genbank accession numbers $\mathrm{MN}-\mathrm{MN}$ ). Only reads from taxonomic families containing macrofauna species were retained, reads from other families or reads assigned at a higher taxonomic level were omitted. OTU's assigned at the family level were manually blasted against the NCBI database and OTU's which returned a trustworthy assignment at the genus level were subsequently assigned. Raw Illumina sequences were deposited in the European Nucleotide Archive (ENA accession number: XXXX - will follow upon acceptance) 


\subsection{Data-analysis}

For the morphological approach, count and biomass data were calculated at the genus level, resulting in a total number of individuals and a total biomass per taxonomic genus per sample. To prevent a bias in the molecular dataset due to variable sequencing depths per sample, read numbers per genus for all molecular samples were transformed into a relative abundance of reads per sample. This transformation was chosen over rarefaction as it does not omit valid read abundance data (McMurdie \& Holmes, 2014; Lanzen et al., 2016). The presence-absence was scored for each taxon per sample and the occurrence was calculated as the sum of total number of presences divided by the total number of samples.

To test the reliability of the frequency of occurrence (FOO) approach, the assumption that a higher occurrence in the morphological method corresponds to a higher detection probability in the molecular method was tested. The square root of the abundance data as derived from the morphological method was used to predict the occurrence in the molecular method based on a logistic regression. The strength of the logistic regression was assessed using Wald's- $\chi^{2}$ and a receiver operating characteristics (ROC) curve. The reliability of the relative read abundance approach (RRA) was tested using a linear regression. This linear regression was based on the square-root of the biomass data for the morphological method and the $\log _{10}$ of the relative read abundance data for the molecular method. As the relative read abundance data contained zeros, the half of the smallest measured value of biomass was added before the data were log-transformed. Unfortunately, detection rates for taxa within the arthropod and mollusc taxa were too low and highly biased in either the morphological or the molecular methods to test these assumptions within these taxa. Therefore, the reliability of the quantitative approaches could only be tested on annelid taxa.

\section{Results}

\subsection{Detection probability}

In total, 23 and 35 macrofauna taxa (genus-level) could be identified from the morphological and molecular samples, respectively (Table 1) of which 22 taxa were identified by both approaches. The molecular approach detected seven extra annelid and six extra mollusc taxa compared to the morphological approach, whereas the arthropod Gammarus was only identified by the morphological approach but not with the molecular approach. The average number of taxa detected per sample was significantly higher $\left(\mathrm{t}_{125}=13.1, \mathrm{p}<0.001\right)$ for the molecular approach $($ mean $=10.0 \pm 2.2)$ than for the morphological approach $($ mean $=6.6 \pm 2.1$ ) (Figure 2).

The detection rates (calculated as percentage of occurrences for all samples) for the 21 most abundant species are visualized in figure 3. A clear discrepancy could be seen for the mollusc and arthropod taxa. The detection rates for arthropod taxa were higher in the morphological samples. For instance, Urothoe was detected in $64 \%$ of the samples for the morphological approach and only in $3 \%$ of the samples in the molecular approach. Mollusc species were overall detected at higher rates in the molecular samples. Five mollusc taxa which were detected in the molecular samples (i.e. Angulus (2.4 \%), Cerastoderma(14.3\%), Crassostrea (28.6\%), Littorina (0.79\%) andPetricolaria (10.3\%)) were never detected in the morphological samples. Detection rates for the annelids were overall higher for both approaches compared to the detection rates of the other phyla. Except for Eteone and Marenzelleria, detection rates for most annelid taxa were higher in the molecular approach.

\subsection{FOO and RRA approach}

To test the reliability of the frequency of occurrence (FOO) approach, the abundance data as derived from the morphological method were modelled using a logistic regression against the occupancy in the molecular dataset. Only the abundance data for Pygospio, as derived from the morphological approach, were a significant predictor for the detection of this taxon within the molecular method (Figure 4, Table 2). For each unit of increase in abundance, the odds of a detection in the molecular approach increased by a factor 1.34 (Wald- $\left.\chi^{2}{ }_{(124)}=3.27, \mathrm{p}=0.001\right)$. Most of the other annelid taxa did, however, show a positive relationship between the abundance in the morphological approach and occurrence in the molecular inventory. The 
only exception was Arenicola for which the odd-ratio of occurrence in the molecular approach declined with increasing abundance.

The sensitivity and specificity for each taxon as based on the logistic regression model is shown in figure 5 as a ROC curve. The degrees of measure for predication ability of the model were calculated based on these plots as the area under curve percentage (AUC, Table 2). The logistic model for Pygsopio was able to predict the presence of this taxon in the molecular approach at a $77 \%$ rate based on the abundance data in the morphological approach. Scoloplos had a predictability of roughly $60 \%$, with a $\chi^{2}$ of 1.52 ; however, for all other species, predictability was lower. The lowest predictability was found for Heteromastus and equaled $52 \%$, which is close to a random guess.

The relative read abundance (RRA) as derived from the molecular method was modelled in a linear regression against the biomass estimates from the morphological method for six annelid taxa (Figure 6, Table 2). The steepest positive slope was found for Pygospio, followed by Tharyx and Scoloplos. The slope found for Pygospiowas significant $\left(\mathrm{F}_{1,40}=12.99, \mathrm{p}<0.001, \mathrm{R}^{2}=0.25\right)$. Capitella and Heteromastusboth showed no relationship between RRA and biomass, whileArenicola displayed a negative slope.

The FOO and the RRA approaches thus both showed roughly the same results. A strong positive relationship was obtained forPygospio. The RRA approach found weak positive relationships for Tharyx and Scoloplos , while, in the FOO approach this was only for Scoloplos. Both approaches showed negative relationships for Arenicola.

\section{Discussion}

The first aim of this study was to examine whether detection rates for benthic macrofauna taxa are comparable between molecular and morphological analyses. The combined use of a morphological as well as a molecular method to quantify the same community allowed us to directly compare the two methods. The detection rates for most arthropod and mollusc taxa were showing opposing results between the two methods, this was slightly better for the annelid taxa. The detection rate of arthropod taxa was higher in the morphological method compared to the molecular method while the opposite was true for most molluscs. Additionally, several mollusc taxa (e.g., Cerastoderma, Crassostrea and Mytilus ) detected by the molecular method were never detected by the morphological method. Explanations for the striking differences in output between the two methods for the different phyla could potentially be sought both in an ecological and a methodological context.

The molecular method identifies and quantifies a target community via the presence of eDNA. This eDNA is a mixture of DNA molecules extracted from bulk environmental samples such as marine sediments (Taberlet et al., 2012a) which include traces of organisms (e.g., hair, faeces, mucus) rather than the organism itself. Therefore, the amount of eDNA in the environment is a result of the biology and ecology of the taxa from which it originates (Barnes \& Turner, 2016). Factors influencing the eDNA exchange of a taxon with the environment could be, among others, its physical appearance, shedding rate, ontogenetic state, growth rate, feeding behaviour or seasonal and spatial patterns. The high detection rate of mollusc taxa within the molecular approach compared to the morphological approach could be due to one or multiple of these factors, especially the combination of spatial patterns and seasonal reproduction patterns. First, seasonal patterns of mollusc species could induce high eDNA presence within spawning periods due to an abundance of gametes and/or larvae. The highest detection rates of Cerastoderma, Crassostrea and Mya were indeed observed in the known spawning periods of these taxa (Supp figure 1, Philippart et al., 2014) whereas detection rates within the morphological approach were close to zero the entire period. Second, the taxa Mytilus and Crassostreaare known to live in high densities at intertidal beds (Folmer et al., 2014) and such a bed was situated approximately 500 meters outside the sampled area during the study period. Even though specimens of these taxa were not found in the morphological approach, eDNA could easily spread and be trapped within the sampled area due to tidal movements. The low detection rate of arthropods in the molecular samples compared to the morphological samples may also be explained by biological factors. Arthropods are characterized by an exterior skeleton made of chitin. This skeleton might inhibit eDNA 
exchange with its environment (Ficetola et al., 2008). Also, in contrast to mollusc taxa, the arthropod taxa found in this study rely on internal fertilization, which minimizes the production of eDNA into the environment. Biases induced due to ecological characteristics of eDNA and its host species have been described scarcely but would deserve a great deal of attention in the future (Stewart, 2019).

Methodological issues within the molecular method which can hamper the quantification of a community have been described extensively (e.g., Elbrecht and Leese, 2015; Lanzén et al., 2017; Alberdi et al., 2018; Kelly et al., 2019 and Pinol et al., 2019). Two key steps necessary to avoid technical biases emerge from these earlier studies: the use of PCR-replicates and the use of a mock community. Alberdi et al. (2017) showed that considerable diversity differences exist between PCR replicates for the same sample, possibly due to PCR stochasticity and/or the accumulation of PCR errors. In the present study, three PCR replicates per sample were included to minimize these biases (Grey et al., 2018). Also, a mock community, an artificial community constructed from DNA extracts from known species was included (Table S1). Such a mock community can help to identify biases induced, e.g., during the sequencing process, during PCR due to a mismatch between a (group of) species and the universal primer, as well as biases induced in the bioinformatics pipeline (Leray and Knowlton, 2016). In our study, the analysis of the mock community showed no indication of a bias in the detection rate of taxa from different phyla, as differences in read numbers were unrelated to phylum. Therefore, biases induced during PCR, sequencing or bioinformatics are assumed to be small in our study.

We concluded that detection rates can be comparable between molecular and morphological analyses, but in the case of marine benthic invertebrates, only for some taxa. Furthermore, the discrepancies we observed between molecular and morphological methods for some taxa are not due to well-known technical artefacts, as we controlled for those, but likely due to taxon-specific differences in ecology. In particular, we expect that the extent to which species leave DNA traces in the environment may differ markedly between taxa and that this leads to skewed detection rates between molecular and morphological approaches among taxa. Thus, great care should be taken when molecular approaches are used for inferences on biomass or abundance.

The second aim of this study was to test the reliability of the frequency of occurrence (FOO) and the relative read abundance (RRA) approach for quantifying marine benthic taxa with molecular methods. For this, the underlying assumptions in these approaches were tested. To summarize, the approaches assumed that a higher abundance or biomass in the morphological dataset leads to a higher detection rate or relative read abundance in the molecular dataset for the FOO and RRA approach, respectively (Deagle et al., 2019). The frequency of occurrence approach is often regarded as a more conservative and robust measurement as the conversion to occurrence data is not impacted by methodological biases such as primer efficiency (Pinol et al., 2019). However, this method is still subject to ecological conditions. Simulations by Deagle et al., (2019) showed that this approach does not necessarily represent overall community abundances as rare taxa might be overestimated. More specifically, for the macrozoobenthic taxa in the intertidal Wadden Sea, Bijleveld et al., (2018) showed that FOO in a morphological dataset does not predict the abundance for all taxa in the same morphological dataset. The predictions in that study were highly influenced by dispersal and aggregation patterns and more reliable predictions could be made for taxa with higher dispersal rates. The same bias might also play a role in the present study. Arenicola, which has holobenthic development, has relatively low dispersal capacity, resulting in an aggregated distribution pattern (Günther, 1992). It showed negative relationships in the FOO approach, whereasPygospio, which is distributed more evenly across mudflats (Gudmundsson, 1985), showed a strong positive relationship. This may be interpreted to indicate that species with an even spatial distribution also distribute their DNA evenly over the environment, while patchily distributed species correspondingly also have patchily distributed DNA, despite, e.g., tidal water movements. DNA-based FOO of the former would then typically not only be higher overall (for their abundance and biomass) but also correlate better with morphology-based FOO than would be the case for patchily distributed taxa.

The relative read abundance approach (RRA) has been discussed to be more influenced by methodological issues than by ecological issues compared to the FOO approach (Deagle et al., 2019; Pinol et al., 2019). These biases will change the relative abundance of taxa compared to each other within a sample. Subsequently, 
this can alter the relative amounts compared to the morphological method. However, the FOO and RRA gave comparable results in this study. A significant positive relationship was found for Pygospio for both approaches compared to the morphological method, also other smaller annelid taxa such as Tharyx and Scoloplos showed a positive but weaker relationship, while the annelid taxon Arenicola showed a negative relationship for both approaches.

The comparable results between the FOO and RRA methods might imply that both methods were subject to the same factors or biases in this study. More elaborate sampling methods are necessary to address the influence of ecological factors in more detail. For this study, a fast and easy molecular sampling method was chosen in which small sediment samples were collected from which DNA was extracted directly. Compared to a method which includes a sieving or elutriation step, this method applies fewer treatments to the samples and has therefore a smaller risk of contamination (Aylagas et al., 2016, Elbrecht et al., 2017). Also, the analysis of smaller metazoan taxa can be included with this method (Brannock \& Halanych 2015). Even though macrofauna taxa might not be best captured with this approach (Klunder et al., 2019), this approach may still have a high potential in future monitoring programs. The choice of sampling approach is possibly reflected in the differences observed among the annelid taxa. Smaller taxa such as Pygospioand Tharyx showed positive correlations with the morphological data set for both the FOO-approach and the RRA-approach whereas bigger taxa with more aggregated distribution patterns such asHeteromastus and Arenicola showed no or even negative correlations with the morphological dataset. Specimens of the smaller taxa might be physically present in the sample while larger metazoan taxa are sampled via their eDNA traces (Taberlet et al., 2012b). Elbrecht et al., (2017) found that read abundance of unsorted samples were dominated by taxa containing higher biomass within the sample and size sorting could help in preventing this bias. However, they also discuss size sorting should only be used when highly necessary to prevent cross-contamination between the samples.

To conclude, this study suggests metabarcoding methods can be quantitative for some marine benthic invertebrate taxa. Smaller annelid taxa displayed moderate correspondence between molecular and morphological data, the latter both for abundance and biomass. However, larger annelid taxa as well as arthropod and mollusc taxa failed to show such correspondence. Moving forward, we suggest to further explore the distribution patterns of eDNA in the environment for different taxa. Ecological factors driving the distribution of eDNA have been described sparsely in the past and only gained scientific interest recently (Stewart, 2019). Before molecular techniques can be widely adopted for inference on abundance and biomass, future studies should encompass these distribution patterns and adjust their experimental design to these patterns to obtain better quantitative measurements.

\section{Data availability}

Raw Illumina sequences were deposited in the European Nucleotide Archive (ENA accession number: XXXX - will follow upon acceptance)

\section{ACKNOWLEDGMENTS}

We are grateful to all the staff and students who helped in collecting field samples, sorting them in the benthic lab and processing them in the molecular lab. We like to thank Giovanni Heijmans, Sophie Watertor and Rowan Stavast in particular.

\section{Author contributions}

LK, AIB, HvdV and PL: conceived the study; LK, LKS and PL: lab and fieldwork; LK: data analysis \& wrote manuscript; LK, AIB, PL, HvdV, LKS and JvB: edited manuscript

\section{References}

Alberdi, A., Aizpurua, O., Gilbert, M. T. P., and Bohmann, K. (2018). Scrutinizing key steps for reliable metabarcoding of environmental samples. Methods Ecol. Evol. 9, 134-147. doi:10.1111/2041-210X.12849. 
Austen, M. C., Lambshead, P. J. D., Hutchings, P. A., Boucher, G., Snelgrove, P. V. R., Heip, C., et al. (2002). Biodiversity links above and below the marine sediment-water interface that may influence community stability. Biodivers. Conserv. 11, 113-136. doi:10.1023/A:1014098917535.

Aylagas, E., Borja, Á., Muxika, I., and Rodríguez-Ezpeleta, N. (2018). Adapting metabarcoding-based benthic biomonitoring into routine marine ecological status assessment networks. Ecol. Indic. 95, 194-202. doi:10.1016/j.ecolind.2018.07.044.

Aylagas, E., Mendibil, I., Borja, Á., and Rodríguez-Ezpeleta, N. (2016). Marine sediment sample preprocessing for macroinvertebrates metabarcoding: Mechanical enrichment and homogenization. Front. Mar. Sci. 3, 1-8. doi:10.3389/fmars.2016.00203.

Barnes, M. A., and Turner, C. R. (2016). The ecology of environmental DNA and implications for conservation genetics. Conserv. Genet. 17, 1-17. doi:10.1007/s10592-015-0775-4.

Berry, T. E., Osterrieder, S. K., Murray, D. C., Coghlan, M. L., Richardson, A. J., Grealy, A. K., et al. (2017). DNA metabarcoding for diet analysis and biodiversity: A case study using the endangered Australian sea lion (Neophoca cinerea). Ecol. Evol. 7, 5435-5453. doi:10.1002/ece3.3123.

Bijleveld, A. I., Compton, T. J., Klunder, L., Holthuijsen, S., Ten Horn, J., Koolhaas, A., et al. (2018). Presence-absence of marine macrozoobenthos does not generally predict abundance and biomass. Sci. Rep. 8, 1-12. doi:10.1038/s41598-018-21285-1.

Brannock, P. M., and Halanych, K. M. (2015). Meiofaunal community analysis by high-throughput sequencing: Comparison of extraction, quality filtering, and clustering methods. Mar. Genomics 23, 67-75. doi:10.1016/j.margen.2015.05.007.

Bucklin, A., Steinke, D., and Blanco-Bercial, L. (2011). DNA Barcoding of Marine Metazoa. Ann. Rev. Mar. Sci. 3, 471-508. doi:10.1146/annurev-marine-120308-080950.

Cahill, A. E., Pearman, J. K., Borja, A., Carugati, L., Carvalho, S., Danovaro, R., et al. (2018). A comparative analysis of metabarcoding and morphology-based identification of benthic communities across different regional seas. Ecol. Evol. 8, 8908-8920. doi:10.1002/ece3.4283.

Cardoso, P., Erwin, T. L., Borges, P. A. V., and New, T. R. (2011). The seven impediments in invertebrate conservation and how to overcome them. Biol. Conserv. 144, 2647-2655. doi:10.1016/j.biocon.2011.07.024.

Chariton, A. A., Court, L. N., Hartley, D. M., Colloff, M. J., and Hardy, C. M. (2010). Ecological assessment of estuarine sediments by pyrosequencing eukaryotic ribosomal DNA. Front. Ecol. Environ. 8, 233-238. doi:10.1890/090115.

Chariton, A. A., Stephenson, S., Morgan, M. J., Steven, A. D. L., Colloff, M. J., Court, L. N., et al. (2015). Metabarcoding of benthic eukaryote communities predicts the ecological condition of estuaries. Environ. Pollut. 203, 165-174. doi:10.1016/j.envpol.2015.03.047.

Compton, T. J., Holthuijsen, S., Koolhaas, A., Dekinga, A., ten Horn, J., Smith, J., et al. (2013). Distinctly variable mudscapes: Distribution gradients of intertidal macrofauna across the Dutch Wadden Sea. J. Sea Res. 82, 103-116. doi:10.1016/j.seares.2013.02.002.

Covich, A. P., Austen, M. C., Bärlocher, F., Chauvet, E., Cardinale, B. J., Biles, C. L., et al. (2004). The role of biodiversity in the functioning of freshwater and marine benthic ecosystems. Bioscience 54, 767-775. doi:10.1641/0006-3568(2004)054[0767:TROBIT]2.0.CO;2.

Cowart, D. A., Pinheiro, M., Mouchel, O., Maguer, M., Grall, J., Miné, J., et al. (2015). Metabarcoding is powerful yet still blind: A comparative analysis of morphological and molecular surveys of seagrass communities. PLoS One 10,1-26. doi:10.1371/journal.pone.0117562.

De Barba, M., Miquel, C., Boyer, F., Mercier, C., Rioux, D., Coissac, E., et al. (2014). DNA metabarcoding multiplexing and validation of data accuracy for diet assessment: application to omnivorous diet. Mol. Ecol. 
Resour. 14, 306-323. doi:10.1111/1755-0998.12188.

Deagle, B. E., Jarman, S. N., Coissac, E., Pompanon, F., and Taberlet, P. (2014). DNA metabarcoding and the cytochrome c oxidase subunit I marker: not a perfect match. Biol. Lett. 10, 20140562-20140562. doi:10.1098/rsbl.2014.0562.

Deagle, B. E., Thomas, A. C., McInnes, J. C., Clarke, L. J., Vesterinen, E. J., Clare, E. L., et al. (2019). Counting with DNA in metabarcoding studies: How should we convert sequence reads to dietary data? Mol. Ecol. 28, 391-406. doi:10.1111/mec.14734.

Diaz, R. J., Solan, M., and Valente, R. M. (2004). A review of approaches for classifying benthic habitats and evaluating habitat quality. J. Environ. Manage. 73, 165-181. doi:10.1016/j.jenvman.2004.06.004.

Elbrecht, V., and Leese, F. (2015). Can DNA-based ecosystem assessments quantify species abundance? Testing primer bias and biomass-sequence relationships with an innovative metabarcoding protocol. PLoS One 10, 1-16. doi:10.1371/journal.pone.0130324.

Elbrecht, V., Peinert, B., and Leese, F. (2017). Sorting things out: Assessing effects of unequal specimen biomass on DNA metabarcoding. Ecol. Evol. 7, 6918-6926. doi:10.1002/ece3.3192.

Ficetola, G. F., Miaud, C., Pompanon, F., and Taberlet, P. (2008). Species detection using environmental DNA from water samples. Biol. Lett. 4, 423-425. doi:10.1098/rsbl.2008.0118.

Ficetola, G. F., Pansu, J., Bonin, A., Coissac, E., Giguet-Covex, C., De Barba, M., et al. (2015). Replication levels, false presences and the estimation of the presence/absence from eDNA metabarcoding data. Mol. Ecol. Resour. 15, 543-556. doi:10.1111/1755-0998.12338.

Folmer, E. O., Drent, J., Troost, K., Büttger, H., Dankers, N., Jansen, J., et al. (2014). Large-Scale Spatial Dynamics of Intertidal Mussel (Mytilus edulis L.) Bed Coverage in the German and Dutch Wadden Sea. Ecosystems 17, 550-566. doi:10.1007/s10021-013-9742-4.

Gray, J. (2000). The measurement of marine species diversity, with an application to the benthic fauna of the Norwegian continental shelf. J. Exp. Mar. Bio. Ecol. 250, 23-49. doi:10.1016/S0022-0981(00)00178-7.

Grey, E. K., Bernatchez, L., Cassey, P., Deiner, K., Deveney, M., Howland, K. L., et al. (2018). Effects of sampling effort on biodiversity patterns estimated from environmental DNA metabarcoding surveys. Sci. Rep. 8, 8843. doi:10.1038/s41598-018-27048-2.

Guardiola, M., Wangensteen, O. S., Taberlet, P., Coissac, E., Uriz, M. J., and Turon, X. (2016). Spatiotemporal monitoring of deep-sea communities using metabarcoding of sediment DNA and RNA. PeerJ 4, e2807. doi:10.7717/peerj.2807.

Gudmundsson, H. (1985). Life History Patterns of Polychaete Species of the Family Spionidae. J. Mar. Biol. Assoc. United Kingdom 65, 93-111. doi:10.1017/S0025315400060835.

Günther, C.-P. (1992). Dispersal of intertidal invertebrates: A strategy to react to disturbance of different scales? Netherlands J. Sea Res. 30, 45-56. doi:10.1016/0077-7579(92)90044-F.

Hebert, P. D. N., Ratnasingham, S., and de Waard, J. R. (2003). Barcoding animal life: cytochrome c oxidase subunit 1 divergences among closely related species. Proc. R. Soc. B Biol. Sci. 270, S96-S99. doi:10.1098/rsbl.2003.0025.

Jeunen, G., Knapp, M., Spencer, H. G., Lamare, M. D., Taylor, H. R., Stat, M., et al. (2019). Environmental DNA (eDNA) metabarcoding reveals strong discrimination among diverse marine habitats connected by water movement. Mol. Ecol. Resour. 19, 426-438. doi:10.1111/1755-0998.12982.

Kelly, R. P., Shelton, A. O., and Gallego, R. (2019). Understanding PCR Processes to Draw Meaningful Conclusions from Environmental DNA Studies. Sci. Rep. 9, 1-14. doi:10.1038/s41598-019-48546-x. 
Klunder, L., Duineveld, G. C. A., Lavaleye, M. S. S., van der Veer, H. W., Palsbøll, P. J., and van Bleijswijk, J. D. L. (2019). Diversity of Wadden Sea macrofauna and meiofauna communities highest in DNA from extractions preceded by cell lysis. J. Sea Res. 152, 101764. doi:10.1016/J.SEARES.2019.101764.

Lamb, P. D., Hunter, E., Pinnegar, J. K., Creer, S., Davies, R. G., and Taylor, M. I. (2019). How quantitative is metabarcoding: A meta-analytical approach. Mol. Ecol. 28, 420-430. doi:10.1111/mec.14920.

Lanzén, A., Lekang, K., Jonassen, I., Thompson, E. M., and Troedsson, C. (2016). High-throughput metabarcoding of eukaryotic diversity for environmental monitoring of offshore oil-drilling activities. Mol. Ecol. 25, 4392-4406. doi:10.1111/mec.13761.

Lanzén, A., Lekang, K., Jonassen, I., Thompson, E. M., and Troedsson, C. (2017). DNA extraction replicates improve diversity and compositional dissimilarity in metabarcoding of eukaryotes in marine sediments. PLoS One 12, 1-18. doi:10.1371/journal.pone.0179443.

Lejzerowicz, F., Esling, P., Pillet, L., Wilding, T. A., Black, K. D., and Pawlowski, J. (2015). High-throughput sequencing and morphology perform equally well for benthic monitoring of marine ecosystems. Sci. Rep. 5, 13932. doi:10.1038/srep13932.

Leray, M., and Knowlton, N. (2016). Censusing marine eukaryotic diversity in the twenty-first century. Philos. Trans. R. Soc. Lond. B. Biol. Sci. 371, 20150331. doi:10.1098/rstb.2015.0331.

Levin, L. A., Boesch, D. F., Covich, A., Dahm, C., Erséus, C., Ewel, K. C., et al. (2001). The function of marine critical transition zones and the importance of sediment biodiversity. Ecosystems 4, 430-451. doi:10.1007/s10021-001-0021-4.

McMurdie, P. J., and Holmes, S. (2014). Waste Not, Want Not: Why Rarefying Microbiome Data Is Inadmissible. PLoS Comput. Biol. 10, e1003531. doi:10.1371/journal.pcbi.1003531.

Patrício, J., Neto, J. M., Teixeira, H., Salas, F., and Marques, J. C. (2009). The robustness of ecological indicators to detect long-term changes in the macrobenthos of estuarine systems. Mar. Environ. Res. 68, 25-36. doi:10.1016/j.marenvres.2009.04.001.

Philippart, C. J. M., van Bleijswijk, J. D. L., Kromkamp, J. C., Zuur, A. F., and Herman, P. M. J. (2014). Reproductive phenology of coastal marine bivalves in a seasonal environment. J. Plankton Res. 36, 15121527. doi:10.1093/plankt/fbu073.

Piñol, J., Mir, G., Gomez-Polo, P., and Agustí, N. (2015). Universal and blocking primer mismatches limit the use of high-throughput DNA sequencing for the quantitative metabarcoding of arthropods. Mol. Ecol. Resour. 15, 819-830. doi:10.1111/1755-0998.12355.

Piñol, J., Senar, M. A., and Symondson, W. O. C. (2019). The choice of universal primers and the characteristics of the species mixture determine when DNA metabarcoding can be quantitative. Mol. Ecol. 28, 407-419. doi:10.1111/mec.14776.

Plummer, E., and Twin, J. (2015). A Comparison of Three Bioinformatics Pipelines for the Analysis of Preterm Gut Microbiota using 16S rRNA Gene Sequencing Data. J. Proteomics Bioinform. 8. doi:10.4172/jpb.1000381.

Pompanon, F., Deagle, B. E., Symondson, W. O. C., Brown, D. S., Jarman, S. N., and Taberlet, P. (2012). Who is eating what: Diet assessment using next generation sequencing. Mol. Ecol. 21, 1931-1950. doi:10.1111/j.1365-294X.2011.05403.x.

Porazinska, D. L., Sung, W., Giblin-Davis, R. M., and Thomas, W. K. (2010). Reproducibility of read numbers in high-throughput sequencing analysis of nematode community composition and structure. Mol. Ecol. Resour. 10, 666-676. doi:10.1111/j.1755-0998.2009.02819.x.

Pruesse, E., Quast, C., Knittel, K., Fuchs, B. M., Ludwig, W., Peplies, J., et al. (2007). SILVA: A comprehensive online resource for quality checked and aligned ribosomal RNA sequence data compatible with ARB. Nucleic Acids Res. 35, 7188-7196. doi:10.1093/nar/gkm864. 
Sinniger, F., Pawlowski, J., Harii, S., Gooday, A. J., Yamamoto, H., Chevaldonné, P., et al. (2016). Worldwide Analysis of Sedimentary DNA Reveals Major Gaps in Taxonomic Knowledge of Deep-Sea Benthos. Front. Mar. Sci. 3, 1-14. doi:10.3389/fmars.2016.00092.

Snelgrove, P. (1997). The Importance of Marine Sediment Biodiversity in Ecosystem Processes. Ambio 26, 578-583. Available at: http://www.jstor.org/stable/4314672\%5Cnhttp://www.jstor.org/stable/4314672?seq=1\&cid=pdfreference\#references_tab_contents\%5Cnhttp://about.jstor.org/terms.

Stewart, K. A. (2019). Understanding the effects of biotic and abiotic factors on sources of aquatic environmental DNA. Biodivers. Conserv. 28, 983-1001. doi:10.1007/s10531-019-01709-8.

Taberlet, P., Coissac, E., Pompanon, F., Brochmann, C., and Willerslev, E. (2012a). Towards next-generation biodiversity assessment using DNA metabarcoding. Mol. Ecol. 21, 2045-2050. doi:10.1111/j.1365-294X.2012.05470.x.

Taberlet, P., Prud'Homme, S. M., Campione, E., Roy, J., Miquel, C., Shehzad, W., et al. (2012b). Soil sampling and isolation of extracellular DNA from large amount of starting material suitable for metabarcoding studies. Mol. Ecol. 21, 1816-1820. doi:10.1111/j.1365-294X.2011.05317.x.

Thrush, S. F., Gray, J. S., Hewitt, J. E., and Ugland, K. I. (2006). Predicting the effects of habitat homogenization on marine biodiversity. Ecol. Appl. 16, 1636-1642. doi:10.1890/1051-0761(2006)016[1636:PTEOHH]2.0.CO;2.

Wang, Q., Garrity, G. M., Tiedje, J. M., and Cole, J. R. (2007). Naïve Bayesian classifier for rapid assignment of rRNA sequences into the new bacterial taxonomy. Appl. Environ. Microbiol. 73, 5261-5267. doi:10.1128/AEM.00062-07.

WoRMS Editorial Board (2019). World Register of Marine Species. Available from http://www.marinespecies.org at VLIZ. Accessed 2019-12-10. doi:10.14284/170

Yin, D., and He, F. (2014). A simple method for estimating species abundance from occurrence maps. Methods Ecol. Evol. 5, 336-343. doi:10.1111/2041-210X.12159@10.1111/(ISSN)1365-2435.ECOLOGYCHINA.

Yu, D. W., Ji, Y., Emerson, B. C., Wang, X., Ye, C., Yang, C., et al. (2012). Biodiversity soup: Metabarcoding of arthropods for rapid biodiversity assessment and biomonitoring. Methods Ecol. Evol. 3, 613-623. doi:10.1111/j.2041-210X.2012.00198.x.

\section{TABLES}

Table 1 | frequency of detections per genus among a total of 126 samples for morphological (Morph) and molecular (DNA) methods.

\begin{tabular}{llllllll}
\hline Taxonomy & Taxonomy & \# Morph & \# DNA & Taxonomy & Taxonomy & \# Morph & \# DNA \\
\hline Annelida & Alitta & 1 & 3 & Annelida & Spio & - & 12 \\
& Arenicola & 104 & 104 & & Streblospio & - & 20 \\
& Capitella & 104 & 107 & & Tharyx & 46 & 123 \\
& Echiura & - & 8 & & & & \\
Eteone & 68 & 20 & Arthropoda & Carcinus & 2 & 2 \\
Eumidia & - & 6 & & Crangon & 38 & 3 \\
Exogone & - & 6 & & Gammarus & 3 & - \\
Glycera & - & 10 & & Urothoe & 81 & 4 \\
Hediste & 9 & 46 & & & & 3 \\
Heteromastus & 42 & 98 & Mollusca & Angulus & - & 18 \\
Lanice & 2 & 89 & & Cerastoderma & - & 36 \\
Magelona & 3 & 1 & & Crassostrea & - & 80 \\
Marenzelleria & 40 & 10 & & Ensis & 2 & 5 \\
Nephtys & 6 & 3 & & Limecola & 16 & 35
\end{tabular}




\begin{tabular}{llllllll}
\hline Taxonomy & Taxonomy & \# Morph & \# DNA & Taxonomy & Taxonomy & \# Morph & \# DNA \\
\hline & Phyllodoce & 4 & 2 & Mytilus & - & 54 \\
& Polydora & - & 3 & Peringia & 2 & 29 \\
& Pygospio & 76 & 94 & Petricolaria & - & 13 \\
Scoloplos & 122 & 110 & & & \\
\hline
\end{tabular}

Table 2 Summary of logistic regression and linear regression as used for FOO (frequency of occurrence) and RRA (relative read abundance) approaches, respectively. For the FOO approach the odd-ratio for positive detection and its confidence interval were calculated, as well as Wald- $\chi^{2}$ and the area under the predictability curve. For the RRA approach, slope of the linear regression, coefficients of determination $\left(\mathrm{R}^{2}\right)$ and $\mathrm{p}$ value are given.

\begin{tabular}{lllllll}
\hline Taxa & FOO - approach & FOO - approach & FOO - approach & FOO - approach & FOO - approach & FOO - appr \\
\hline & Odd-ratio & $2.5 \%$ & $97.5 \%$ & Wald- $\chi^{2}$ & $\mathrm{p}$ & AUC $(\%)$ \\
Arenicola & -0.84 & -0.62 & -1.14 & 1.37 & 0.242 & 55 \\
Capitella & 1.05 & 0.98 & 1.16 & 1.25 & 0.263 & 55 \\
Heteromastus & 1.19 & 0.73 & 2.13 & 0.42 & 0.518 & 52 \\
Pygospio & 1.34 & 1.16 & 1.66 & 10.7 & $0.001^{*}$ & 77 \\
Scoloplos & 1.48 & 0.70 & 3.16 & 1.52 & 0.218 & 59 \\
Tharyx & 1.06 & 0.55 & 4.67 & 0.02 & 0.899 & 63 \\
\hline
\end{tabular}

\section{FIGURE LEGENDS}

Figure 1 | Map of Texel, showing the sampling locations at the intertidal mudflats, NE of Texel. Also, a graphical display of the sampling scheme is shown.

Figure 2 Histogram showing frequency distribution of number of macrofauna taxa (genus) identified per sample for morphological (black) and molecular method (white). The grey area indicates overlap.

Figure 3 | occurrence per taxon, calculated as the sum of detections divided by the total number of samples $(\mathrm{n}=126)$ for both the morphological method (x-axis) and the molecular method (y-axis). Taxa detected belonged to three phyla: Annelida (red circles), Arthropoda (green triangles) or Mollusca (blue squares).

Figure 4 | logistic regression and abundance distribution histograms for six annelid taxa. The abundance distribution as derived from the morphological method are shown in histograms at the sqrt-transformed xaxis. The y-axis shows the occurrence of this taxon in the molecular dataset for the corresponding samples.

Figure 5 | ROC (receiver operating characteristics) curve as derived from the logistic regression for six annelid taxa. The ROC curve shows the sensitivity on the y-axis, calculated as the true positive predictions by the logistic model and the specificity, calculated as the false positive predictions, on the x-axis.

Figure 6 | Relative read abundance (RRA) approach relationships for six annelid taxa. The square-root of biomass estimates as derived from the morphological method are shown on the $\mathrm{x}$-axis and the $\log _{10}$ of the relative read abundance of the same sample in the molecular dataset is shown on the y-axis.

\section{Supplementary files}



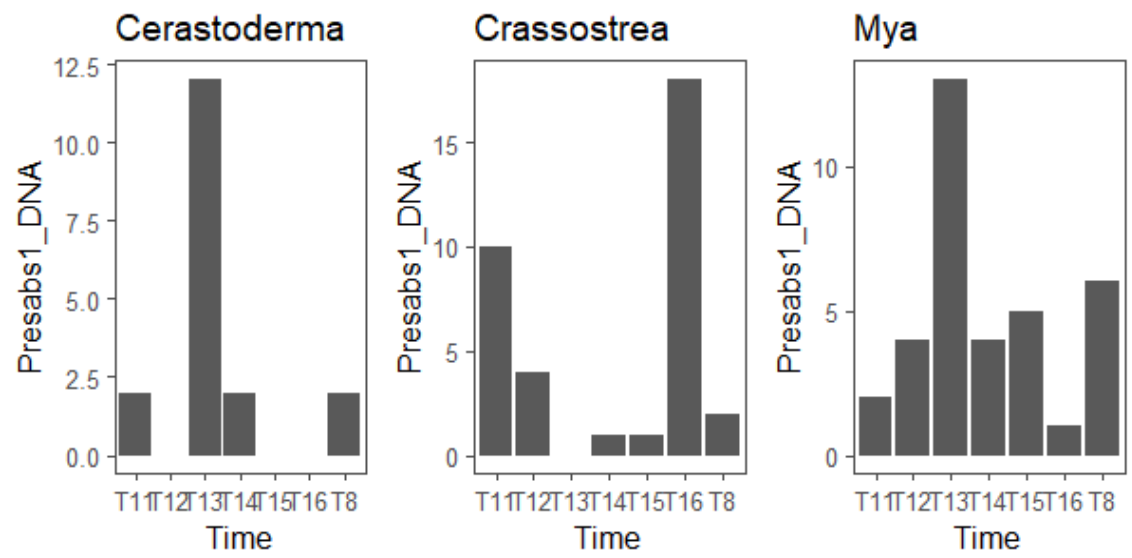

Supp figure 1 : number of detections of Cerastoderma, Crassostrea and Mya within the molecular approach per sampling event $(\mathrm{n}=18)$. Time codes correspond to: T11 - November, T12 - March, T13/T14 - May, T15/T16 - June

\section{Supp Table 1: Mock community}

\section{Hosted file}

image2.emf available at https://authorea.com/users/307921/articles/438892-quantification-ofmarine-benthic-communities-with-metabarcoding-is-highly-influenced-by-ecological-factors

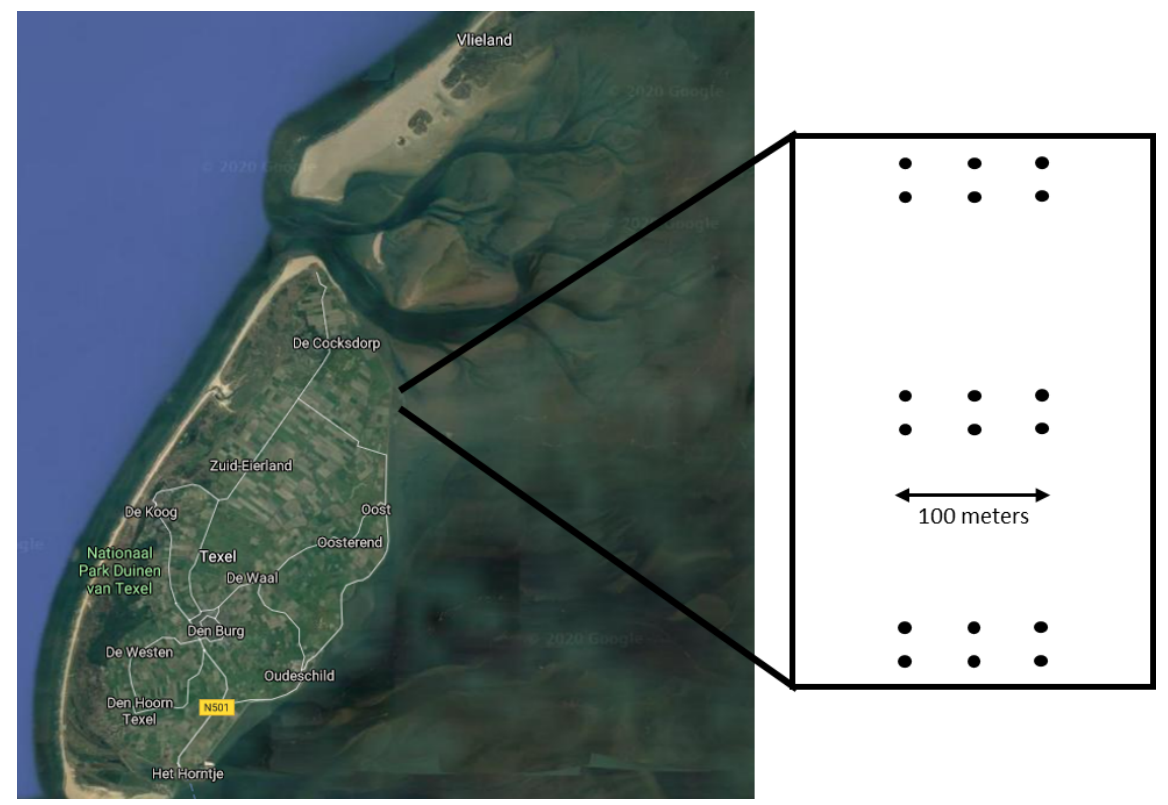




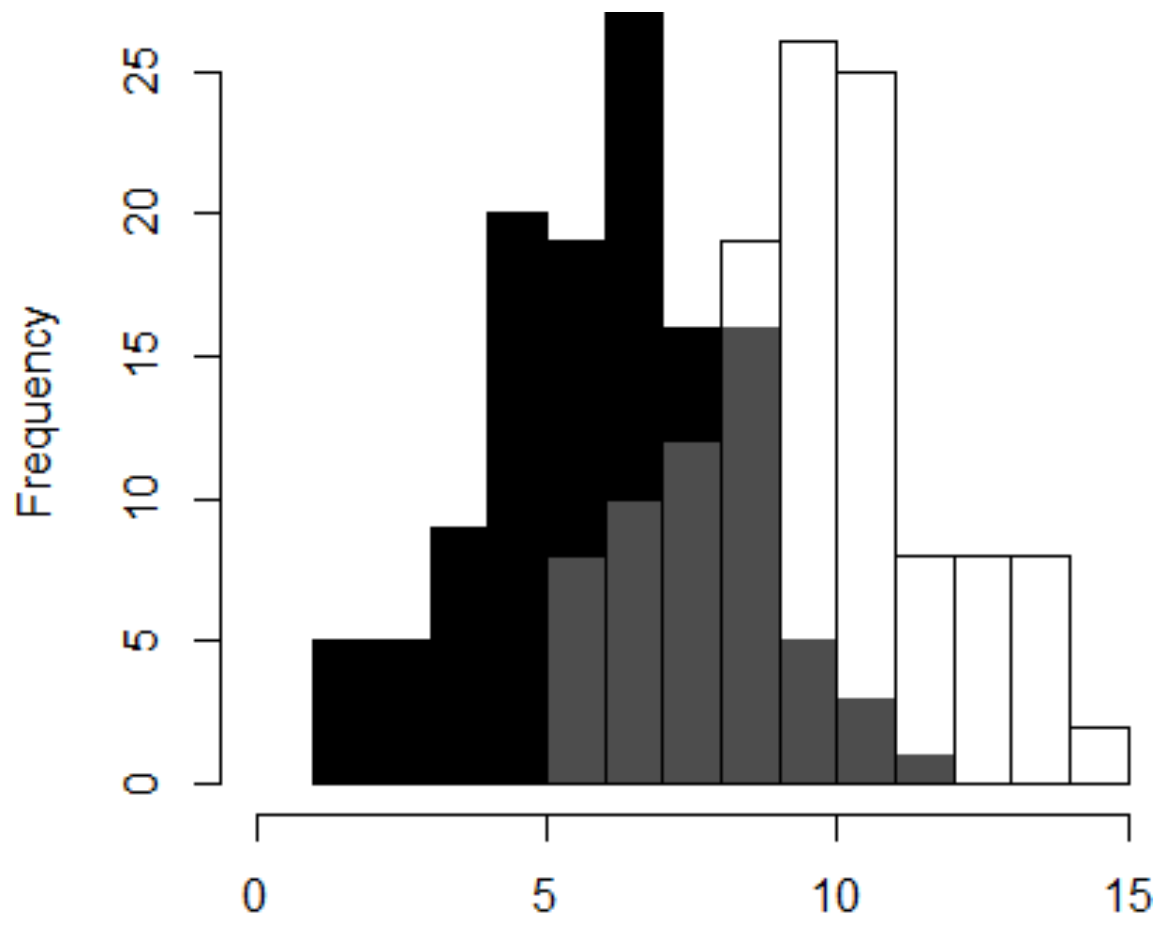

Number of taxa per sample

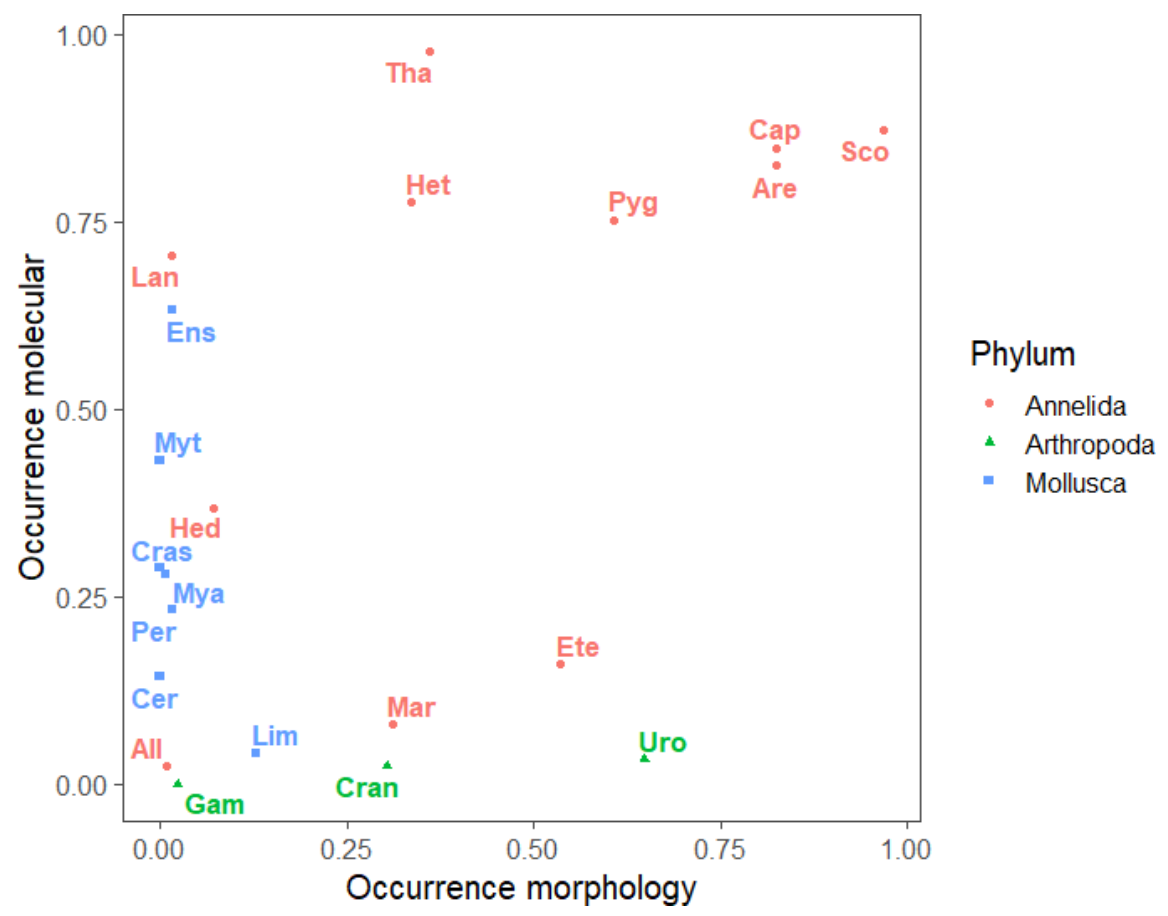



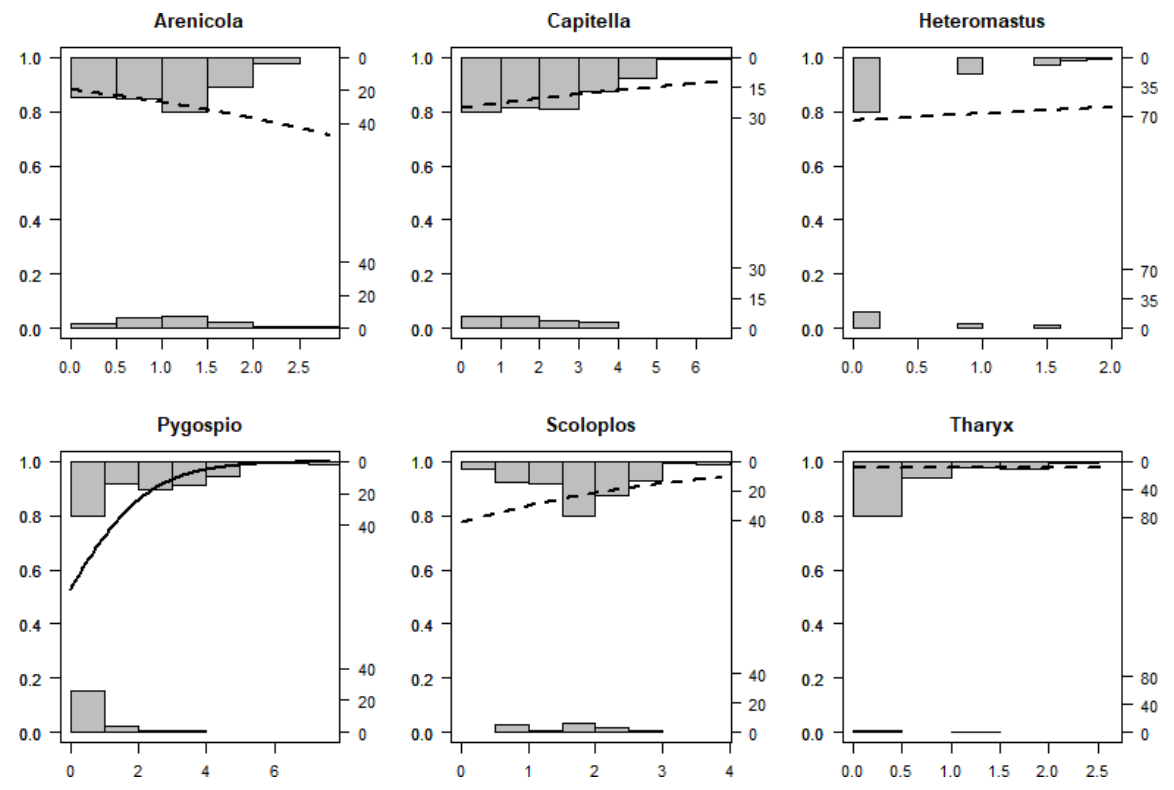

ROC curve

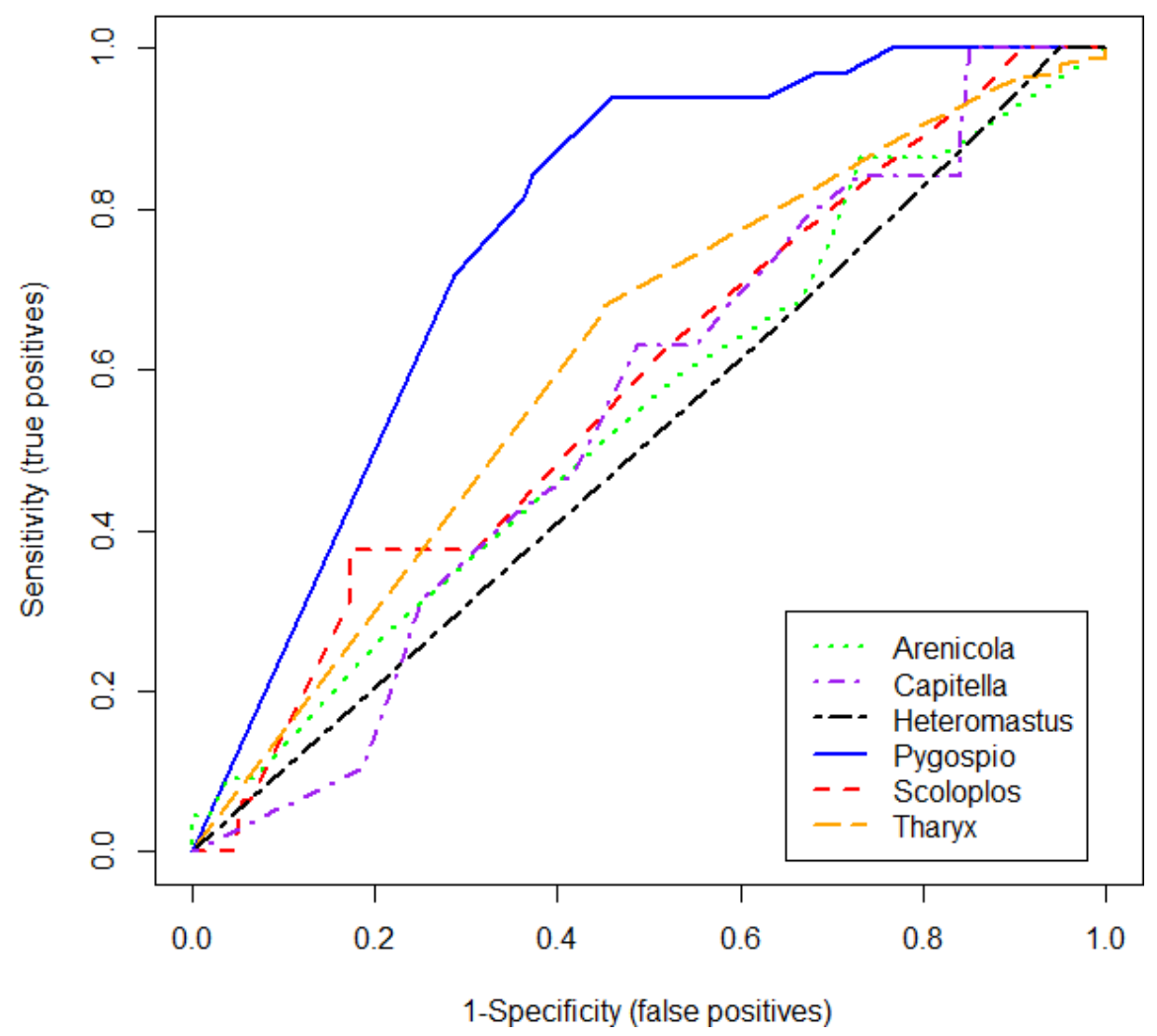



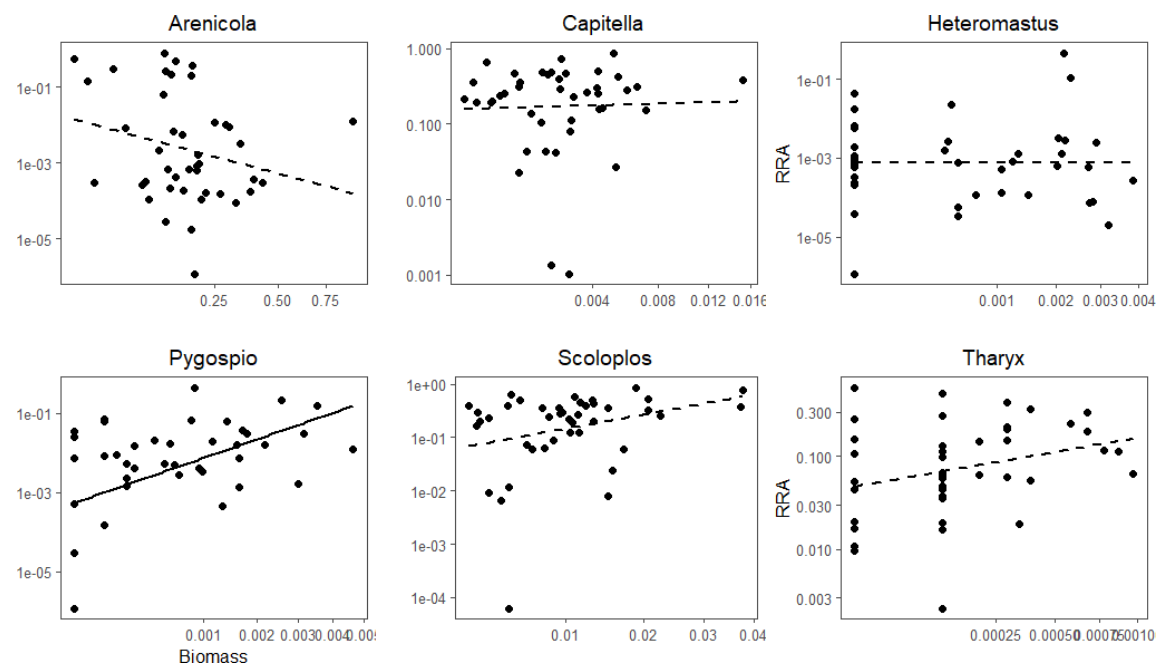